\title{
MESTRADO PROFISSIONAL E O DESENVOLVIMENTO PROFISSIONAL DO PROFESSOR DE MATEMÁTICA
}

\section{Professional master's degree and the professional development of the Mathematics teacher}

\author{
Célia Maria Carolino Pires ${ }^{1}$. Sonia Barbosa Camargo Igliori ${ }^{1}$
}

\begin{abstract}
Resumo: O objetivo deste artigo é apresentar resultados de pesquisa sobre um curso de Mestrado Profissional em Educação Matemática, implantado, em 2002, na PUC/SP. Em sua trajetória, transformações ocorreram, mas a divulgação da etapa inicial dessa experiência permanece oportuna para contribuir com a discussão sobre o desenvolvimento profissional de professores, e sobre essa modalidade de pós-graduação stricto sensu. Trata-se do estudo de um caso com a finalidade de ilustrar o debate de um tema, e tem um sentido descritivo. Os dados foram coletados em documentos do processo de criação do curso, em entrevistas com alunos e no levantamento dos temas dos cem primeiros trabalhos de conclusão. As análises dos dados indicam que a formação do professor é um processo que envolve inserções em diferentes domínios de conhecimento, que é importante adotar a concepção do professor como pesquisador, e tornar possível o desenvolvimento da pesquisa articulada ao trabalho docente.
\end{abstract}

Palavras-chave: Mestrado Profissional. Educação Matemática. Desenvolvimento profissional. Trabalho docente.

\begin{abstract}
This article present the results of research conducted on a course for Professional Masters in Mathematics Education, implemented in 2002, in college PUC/SP. In its history, changes occurred, but the timely dissemination of this experience is a way to contribute to the discussion about the professional development of teachers, and this type of postgraduate study. It is a case study in order to illustrate the discussion of a topic, and has a descriptive approach. Data were collected from documents in the course their development, interviews with students, and a survey of the first 100 candidates on conclusion. Analyses of the data indicate that teacher training is a process that involves incursions into different fields of knowledge, it is important to adopt the concept of the teacher as researcher, and make possible the development of research practice that relates to teaching.
\end{abstract}

Keywords: Professional master. Mathematics education. Professional development. Mathematics teacher.

\footnotetext{
${ }^{1}$ Pontifícia Universidade Católica de São Paulo (PUCSP), Faculdade de Ciências Exatas e Tecnologia, Departamento de Matemática, Rua Marquês de Paranaguá, 111, Consolação, CEP 01303-050, São Paulo, SP, Brasil.E-mail: celia@pucsp.br
} 
Pires, C. M. C.; Igliori, S. B. C.

\section{Introdução}

Decorridos cerca de 18 anos de criação de mestrados profissionais no Brasil, o debate em torno das questões sobre essa modalidade de pós-graduação continua. Esta pesquisa tem o propósito de contribuir com essas discussões. Ela traz uma investigação referente a um curso de Mestrado Profissional em Educação Matemática que teve início em agosto de 2002, constituindo-se estudo de um caso que entendemos significativo.

A pesquisa, de abordagem qualitativa, teve início assim que o curso foi aprovado e implementado e estendeu-se até 2008. O interesse principal era o de acompanhar o seu desenvolvimento, compreender sua identidade e delinear o perfil dos estudantes da primeira turma, buscando caracterizar melhor as aspirações específicas de um público novo da pós-graduação. Conforme Donaire (1997, p. 10), configura-se como estudo de caso na medida em que realiza "um estudo empírico que investiga um fenômeno atual dentro de seu contexto real, no qual as fronteiras entre o fenômeno e o contexto não são claramente definidas."

As questões da pesquisa foram aquelas que se apresentaram desde a proposição do curso. Algumas mais gerais de um Mestrado Profissional (MP), como: qual a caracterização de um MP, no caso particular, um Mestrado Profissional em Educação Matemática? Qual sua identidade? Como organizar seu projeto curricular de modo a lhe conferir essa identidade? Que demandas de formação atender? E outras mais específicas ao curso investigado, como: Qual o perfil dos ingressantes nesse curso? Quais os temas de interesse dos professores mestrandos? O curso favorece o tratamento da articulação pesquisa e prática?

As referências teóricas para a análise dos dados foram aquelas que nortearam o projeto do curso, sobretudo as orientações sobre a formação de professores de Ponte (1992), Perrenoud (2000), Tardif (2002), Ball (1988) e Elbaz (1983).

Neste artigo são apresentados os resultados deste estudo, incluindo: a retrospectiva da criação e implantação do curso (com vistas a situar as condições da criação do curso); as principais referências teóricas que sustentaram a concepção do projeto curricular (contextualizar teoricamente); perfil e anseios do professor/mestrando (características dos alunos do curso) obtidos por meio de entrevistas ${ }^{2}$ respondidas espontaneamente por um grupo de trinta alunos ${ }^{3}$; temas abordados em trabalhos de conclusão, a partir de um levantamento feito dos cem primeiros concluintes, buscando identificar a influência do contato com a pesquisa na formação desses professores.

\footnotetext{
${ }^{2}$ As entrevistas constavam de questões abertas com vistas a favorecer a obtenção de informações sobre: as motivações dos estudantes para cursar o Mestrado Profissional; a interferência do curso no seu desenvolvimento profissional e na atuação docente; as aprendizagens identificadas por eles como significativas para esse fim, e sobre a possível ampliação do universo cultural.

${ }^{3}$ A primeira turma do curso era composta de trinta alunos, e todos foram convidados a participar das entrevistas, respondendo positivamente.
} 
Mestrado Profissional e o desenvolvimento ...

\section{Retrospectiva da criação e implantação do curso}

Em 1995, a Coordenação de Aperfeiçoamento de Pessoal de Nível Superior (Capes), tendo em vista o documento intitulado "Programa de Flexibilização do Modelo de Pós-Graduação Senso Estrito em Nível de Mestrado", aprovado pelo Conselho Superior, determinava implantação de procedimentos apropriados à recomendação, acompanhamento e avaliação de cursos de mestrado dirigidos à formação profissional, nos termos do referido documento e do parecer que o fundamentava. Destacava que, para assegurar níveis de qualidade comparáveis aos vigentes no sistema de pós-graduação e consistentes com a especificidade dos cursos, ficariam estabelecidos diversos requisitos e condicionantes.

Em primeiro lugar, a instituição proponente deveria demonstrar possuir condições favoráveis ao desenvolvimento consistente e de longo alcance do ensino de pós-graduação, assegurando-lhe profundidade e perspectiva adequadas. Destacava que os docentes e orientadores deveriam ser portadores do título de doutor ou de qualificação profissional inquestionável. Dos docentes doutores exigir-se-ia que tivessem produção intelectual de alto nível, divulgada de acordo com os padrões reconhecidos para sua área de conhecimento. Previa-se que docentes selecionados por qualificação profissional poderiam atuar como co-orientadores. Esses deveriam constituir uma parcela restrita do corpo docente, e sua escolha deveria ser pertinente aos objetivos do curso, cuidadosamente justificada, documentada e controlada; as condições de trabalho e de carga horária, embora sem exigirem dedicação integral, deveriam ser compatíveis com as necessidades do curso.

A Capes orientava que o curso deveria articular as atividades de ensino com as aplicações de pesquisas, em termos coerentes com seu objetivo, de forma diferenciada e flexível. A existência de pesquisa de boa qualidade na instituição e de projetos em parceria com o setor produtivo, bem como a oferta de atividades de extensão, eram requisitos essenciais ao credenciamento institucional para oferta desse tipo de curso. Exigia que a estrutura curricular fosse clara e consistentemente vinculada à especificidade do curso e compatível com um tempo de titulação mínimo de um ano.

O estudante deveria apresentar trabalho final que demonstrasse domínio do objeto de estudo e capacidade de expressar-se lucidamente sobre ele. A CAPES inovava ainda, propondo que, de acordo com a natureza da área e com a proposta do curso, esse trabalho poderia tomar formas como, entre outras: dissertação, projeto, análise de casos, performance, produção artística, desenvolvimento de instrumentos, equipamentos e protótipos.

Mesmo com os aportes legais, muitas dúvidas e receios estavam presentes na organização desses cursos. Como caracterizar um Mestrado Profissional, no caso particular, um Mestrado Profissional em Educação Matemática? Qual sua identidade? Como organizar seu projeto curricular de modo a lhe conferir essa identidade? Que demandas de formação atender? O que esperam os ingressantes nesses cursos? 
A Pontifícia Universidade Católica de São Paulo (PUC-SP) oferecia, desde 1994, no âmbito do Programa de Estudos Pós-Graduados em Educação Matemática, o Mestrado Acadêmico em Educação Matemática, e era assim credenciado para propor um projeto de Mestrado Profissional. Mesmo assim, fazendo uma retrospectiva, é importante relembrar que a implantação do Mestrado Profissional, em seu início, enfrentou vários entraves, típicos de experiências inovadoras porque havia questionamentos sobre a própria existência do Mestrado Profissional e sobre sua identidade como curso de pós-graduação stricto sensu.

O Programa de Estudos Pós-Graduados em Educação Matemática da PUC-SP considerava que o Mestrado Profissional poderia ser uma resposta a uma necessidade socialmente definida, de capacitação profissional de natureza diferente da propiciada pelo Mestrado Acadêmico, e que não se contrapunha, sob nenhum ponto de vista, à oferta e expansão dessa última modalidade de curso, nem se constituía em uma alternativa para a formação de mestres segundo padrões de exigência mais simples ou menos rigorosos do que aqueles tradicionalmente adotados pela pós-graduação.

Para esse Programa, a demanda por um curso de Mestrado Profissional em Educação Matemática no Estado de São Paulo estava bem caracterizada pelas experiências de formação continuada de professores de Matemática desenvolvidas no âmbito de projetos como o PróCiências e o Programa de Educação Continuada da Secretaria da Educação do Estado de São Paulo (PEC). Essas experiências evidenciavam o grande interesse por cursos de pós-graduação por parte dos professores, particularmente das redes públicas, que buscavam novas formas de atualização.

Além disso, nos diálogos entre a PUC-SP e a Secretaria da Educação do Estado de São Paulo (SEE-SP), enfatizava-se sempre que as alternativas de formação continuada comumente oferecidas aos professores dos ensinos Fundamental e Médio - com cursos de curta duração desarticulados de sua prática - não produziam os resultados esperados e desejados. Desse modo, o Mestrado Profissional, organizado com currículo que contemplasse tanto conhecimentos específicos de uma área como a formação didático-pedagógica de forma articulada com a pesquisa nessa área, constituiria uma alternativa potencialmente interessante para atender à demanda identificada e enfrentar os problemas característicos da formação continuada do profissional da Educação.

O projeto do Mestrado Profissional em Educação Matemática da PUC-SP levou em conta normas da CAPES que orientavam no sentido de que ele deveria ter caráter de preparação profissional na área docente, focalizando o ensino, a aprendizagem, o currículo, a escola e o sistema escolar. Esse projeto deveria também contribuir efetivamente para a evolução do Sistema de Ensino, seja pela ação direta em sala de aula, pela ação em espaços educativos em que a atuação do professor é fundamental: escola, comunidade, associações científicas etc.

Do ponto de vista legal, o curso de Mestrado Profissional deveria atender a diferentes requisitos e condições, e entre eles, destacavam-se: a inarredável manutenção de níveis de qualidade condizentes com os padrões da pós-graduação stricto sensu e consistentes com a feição peculiar do Mestrado dirigido à formação profissional; a exigência de apresentação de trabalho final que demonstrasse domínio do objeto de estudo (sob a forma de dissertação, projeto, análise de casos, performance, produção artística, desenvolvimento de instrumentos, equipamentos, protótipos, entre outras, de acordo com a natureza da área e os fins do curso) e capacidade de expressar-se lucidamente sobre ele. 
Mestrado Profissional e o desenvolvimento ...

\section{As principais referências teóricas do Projeto/pesquisa}

Ao se retomarem as origens do curso, é pertinente retomar as referências teóricas que direcionaram a elaboração do projeto curricular do mesmo. Nelas é possível identificar autores e ideias subjacentes aos eixos estruturantes do projeto: adoção da concepção de desenvolvimento profissional, articulação entre conhecimentos teóricos e práticos, inserção dos professores na pesquisa acadêmica preservando seus vínculos com as práticas docentes.

Um ponto fundamental foi a consideração de que tal modalidade de curso não poderia ser a de um simples curso a frequentar, mas um espaço de formação mais ampla, com modalidades distintas de atividades curriculares e, em particular, a investigação sobre a sala de aula e a construção de conhecimento pedagógico. Nesse sentido, sua concepção deveria inserir-se no que diferentes autores denominam "desenvolvimento profissional", para dar a ideia de que a capacitação do professor para o exercício da sua atividade profissional é um processo que envolve múltiplas etapas e que, em última análise, está sempre incompleto.

Um desses autores é João Pedro da Ponte, para quem, embora a formação esteja muito associada à ideia de "frequentar" cursos, o desenvolvimento profissional ocorre por meio de múltiplas formas, que incluem cursos, mas, também, atividades como: projetos, trocas de experiências, leituras, reflexões etc. Saraiva e Ponte (2003) destacam ainda que, na formação tradicional, o movimento é essencialmente de fora para dentro, cabendo, ao professor, assimilar os conhecimentos e a informação que lhe são transmitidos; enquanto numa perspectiva de desenvolvimento profissional teríamos um movimento de dentro para fora, cabendo, ao professor, as decisões fundamentais relativamente às questões que quer considerar, aos projetos que quer empreender e ao modo como os quer executar. Ao defender a ideia de desenvolvimento profissional, esses autores destacam a importância de que, nesse processo, sejam consideradas a teoria e a prática, de forma interligada, em contraposição à formação tradicional que parte, em geral, da teoria e, dificilmente, chega à prática.

Outro aspecto de destaque na literatura sobre formação de professores, especialmente importante, refere-se à articulação entre teoria e prática, sobretudo o tratamento a respeito de Philippe Perrenoud, Maurice Tardif e Freema Elbaz.

Perrenoud (2000) refere-se ao conhecimento do professor como um conhecimento na ação. Ele utiliza o termo competência como uma capacidade de mobilizar diversos recursos cognitivos para enfrentar um tipo de situação. Para esse autor, as competências profissionais constroem-se em formação, mas, também, na ação diária de um professor.

Tardif (2002) também ressalta que os saberes profissionais dos professores são situados, pois são construídos e utilizados em função de uma situação de trabalho particular e ganham sentido nessa situação. Portanto, trata-se de um conhecimento de natureza situada, ou seja, resultante da cultura e do contexto em que o professor adquire seus conhecimentos e da circunstância em que atua. Esse autor chama a atenção para o fato de que os saberes profissionais não são construídos e utilizados em função de transferência ou generalização, mas estão ligados fortemente a uma situação de trabalho à qual devem atender. Para esse autor, o conhecimento do professor é caracterizado ainda pela sua diferença em relação ao conhecimento de um especialista na disciplina, e tem um forte componente do saber a disciplina para ensiná-la.

Elbaz (1983) destaca o contexto escolar como parte integrante dos conhecimentos dos professores. Essa faceta, segundo a autora, inclui: os estilos de aprendizagem dos alunos, 
os interesses, as necessidades e as dificuldades dos alunos, um repertório de técnicas de ensino e competências de gestão de sala de aula.

No tocante à questão da inserção de professores no mundo da pesquisa acadêmica, tomaram-se em conta as considerações de Zeichner (1992), de que a maior parte dos professores não procura a pesquisa educacional acadêmica para instruir ou melhorar suas práticas. Ele destaca que, geralmente, o conhecimento gerado por meio da pesquisa educacional acadêmica é apresentado de forma a não levar os professores a se engajar nela intelectualmente. Seus resultados são apresentados como definitivos, inquestionáveis, ou usados para impor algum programa prescritivo a ser seguido pelos professores. Ele acredita que talvez, por essas razões, os professores acabam se afastando das pesquisas acadêmicas. Outro motivo importante para esse afastamento é a forma negativa pela qual os professores são descritos nessas pesquisas.

Zeichner (1992) comenta que muitos acadêmicos, nas universidades, rejeitam as pesquisas realizadas por professores das escolas de Ensino Básico por considerá-las menos relevantes. Tais pesquisas não são consideradas como produção de conhecimento, elas não são citadas em trabalhos acadêmicos, nem utilizadas em cursos de formação de professores.

Zeichner (1992) acredita na pesquisa colaborativa, na qual professores e pesquisadores das universidades trabalham em parceria, não com uma igualdade absoluta, pois cada qual tem seus conhecimentos específicos para a colaboração, mas com paridade no relacionamento, com respeito ao conhecimento do outro e à contribuição que cada um pode dar. Ele acredita que a pesquisa colaborativa vai fazer com que a divisão entre professores e pesquisadores acadêmicos tenha fim. Enfatiza que é preciso julgar trabalhos com critérios, e que há bons e maus trabalhos tanto de professores como de pesquisadores acadêmicos.

O autor conclui que é possível ultrapassar a linha divisória entre os professores e os pesquisadores acadêmicos de três modos: a) comprometendo-se com os professores a realizar ampla discussão sobre o significado e a relevância da pesquisa que conduzimos; b) empenhando-se com processos de pesquisa que permitam desenvolver uma colaboração genuína com os professores, rompendo com os velhos padrões de dominação acadêmica; c) dando suporte às investigações feitas por professores, ou aos projetos de pesquisa-ação, e acolhendo, seriamente, os resultados desses trabalhos como conhecimentos produzidos.

Para Zeichner (1992), é necessário que sejam alteradas estruturas das instituições formadoras a fim de que professores acadêmicos possam dedicar-se às escolas de Educação Básica. Em muitas universidades, ocorre que quanto mais próxima a pesquisa estiver do professor desse nível de ensino, mais baixo é seu status e menor sua chance de se obter financiamento.

Outro aspecto relevante é o de que a pesquisa-ação será uma forma de trabalho privilegiada, considerando-se o professor como sujeito do processo de produção do conhecimento, levando em conta autores como Zeichner (1992), que consideram a pesquisa-ação um instrumento fundamental para se conhecer problemas de ensino, possibilitando reorganizações de políticas educacionais. Desse modo, considerou-se que uma importante meta para esses cursos é o fortalecimento das pesquisas com professores e de professores em relação o processo de ensino aprendizagem.

Nos últimos anos, tem-se visto o surgimento de pesquisas cooperativas e colaborativas. Para Boavida e Ponte (2002), a colaboração constitui uma estratégia fundamental para lidar com problemas que se afiguram demasiado pesados para serem enfrentados individualmente. Também ressalta que, para a investigação sobre a prática, a colaboração oferece impor- 
tantes vantagens que a tornam um valioso recurso. Algumas razões para que isso se verifique residem no fato de que juntando-se diversas pessoas empenhando-se em um objetivo comum, reúnem-se, por si só, mais energias do que as que possuem uma única pessoa, fortalecendo-se, assim, a determinação em agir; juntando-se diversas pessoas com experiências, competências e perspectivas diversificadas, reúnem-se mais recursos para concretizar, com êxito, um dado trabalho, havendo, por conseguinte, um acréscimo de segurança para promover mudanças e iniciar inovações; juntando-se diversas pessoas que interagem, dialogam e refletem em conjunto, criam-se sinergias que possibilitam uma capacidade de reflexão acrescida e um aumento das possibilidades de aprendizagem mútua, permitindo, assim, ir muito mais longe e criando melhores condições para enfrentar, com êxito, as incertezas e obstáculos que surgem.

Para Zeichner (1993), os professores estão sempre a teorizar, à medida que são confrontados com os vários problemas pedagógicos, tais como a diferença entre as suas expectativas e os resultados. A teoria pessoal de um professor sobre a razão por que uma lição de leitura ocorreu pior, ou melhor, do que esperado, é tanto teoria como as teorias geradas nas universidades sobre o ensino de leitura: ambas precisam ser avaliadas quanto à sua qualidade, mas as duas são teorias sobre a realização de objetivos educacionais.

Também Anderson e Herr (1999), analisando a natureza e a especificidade das pesquisas realizadas por "práticos", indicam que essas pesquisas são pouco valorizadas e, mesmo, consideradas estranhas para os pesquisadores que trabalham sob a égide de paradigmas acadêmicos de pesquisa.

No trabalho que realizaram, Cochran-Smith e Lytle (1999) afirmam que, na maioria dos estudos, os professores são objetos das investigações dos pesquisadores, e espera-se que sejam consumidores e implementadores desses resultados. O que está faltando são as vozes dos próprios professores, as questões trazidas por eles e os quadros referenciais interpretativos que eles usam para compreender e melhorar sua própria prática de sala de aula.

\section{Os objetivos do Curso}

$\mathrm{Na}$ elaboração do projeto curricular do curso, podem-se distinguir dois tipos de objetivos: aqueles vinculados às proposições teóricas dos autores escolhidos como referências, $\mathrm{e}$ aqueles inerentes a um curso de mestrado. Com esses pressupostos, os objetivos constantes do projeto foram assim delineados:

Ampliar, aprofundar e aprimorar o processo de formação de professores que lecionam Matemática na Educação Básica ou Superior; e Professores-coordenadores desses níveis de ensino para que possam transformar sua prática docente; Desenvolver uma formação apoiada na apropriação de conhecimentos de pesquisas em Educação Matemática para que esses profissionais possam utilizá-las em sua prática; Contribuir para a apropriação dos profissionais, de novos paradigmas de produção científica, que respondam mais satisfatoriamente ao problema da fragmentação nos modelos curriculares vigentes, na área de Matemática; Difundir conhecimentos relativos à Didática da Matemática 
Pires, C. M. C.; Igliori, S. B. C.

\begin{abstract}
e suas implicações na atuação docente, mantendo intercâmbios com centros nacionais e internacionais que desenvolvem pesquisas sobre Educação Matemática e formação de professores; Produzir conhecimentos sobre o ensino de Matemática a partir da tematização da prática dos profissionais mestrandos, importante fonte de saber para a formação inicial de outros professores; Conferir, mediante as exigências acadêmicas do Programa, o grau de Mestre Profissional em Educação Matemática. (PONTIFÍCIA UNIVERSIDADE CATÓLICA DE SÃO PAULO, 2004)
\end{abstract}

Nesses objetivos, pode-se observar a decisão de que os professores mestrandos ppoderiam aprofundar e ampliar seus conhecimentos matemáticos, particularmente os que são ensinados por eles a alunos da Educação Básica, apropriando-se das contribuições das pesquisas na área de Educação Matemática e formulando novas questões relativas à pratica docente do professor de Matemática.

Para tanto, mostrou-se necessário organizar um currículo de formação que instituísse tempos e espaços curriculares diferenciados, ou seja, além de abordagens disciplinares e que pudessem incluir: seminários longitudinais, ciclos de palestra, grupos de estudo, estudo individual com uso de novas tecnologias, programação de exposições e debates de trabalhos realizados, participação em atividades programadas.

\title{
A estrutura curricular do curso
}

Com as perspectivas indicadas nas referências teóricas, o currículo do curso de Mestrado Profissional em Educação Matemática, que compreendia um total de trinta créditos ${ }^{4}$ foi composto por disciplinas direcionadas para os temas matemáticos e didáticos, organizadas de modo a enfatizar um desses aspectos, mas sempre buscando articulações entre eles. Além das disciplinas, o curso compreendia: Atividades Complementares; Atividades de Prática Docente e Desenvolvimento de Pesquisa, conforme indica o Quadro 1.

As disciplinas estavam organizadas em dois blocos: a) disciplinas referentes aos conhecimentos matemáticos: Tópicos de Cálculo Diferencial e Integral, Tópicos de Álgebra, Tópicos de Geometria, Tópicos de Estatística e Probabilidade, e Introdução à Filosofia e à História da Matemática; b) disciplinas referentes aos conhecimentos didático-pedagógicos: Didática da Matemática, Desenvolvimento Curricular em Matemática e Aspectos Cognitivos da Aprendizagem Matemática.

\footnotetext{
${ }^{4}$ A unidade de crédito equivale a cinco horas de atividades, correspondendo a aulas teóricas, leituras dirigidas, preparação de seminários, atividades de pesquisa e preparo de dissertação (Trabalho final). A integralização de cada crédito corresponde a 17 semanas, totalizando, assim, 85 horas-atividade.
} 
Mestrado Profissional e o desenvolvimento ...

Quadro 1. Componentes curriculares e tempo destinado.

\begin{tabular}{|l|c|c|}
\hline \multicolumn{1}{|c|}{ Componentes curriculares } & Créditos & Horas-atividade \\
\hline Disciplinas & 18 & $1.530 \mathrm{~h} / \mathrm{a}$ \\
\hline Atividades complementares & 06 & $510 \mathrm{~h} / \mathrm{a}$ \\
\hline Prática docente supervisionada & 03 & $255 \mathrm{~h} / \mathrm{a}$ \\
\hline Desenvolvimento do trabalho final & 03 & $255 \mathrm{~h} / \mathrm{a}$ \\
\hline Total & $\mathbf{3 0}$ & $\mathbf{2 . 5 5 0} \mathbf{~ h / a}$ \\
\hline
\end{tabular}

Fonte: Pontifícia Universidade Católica de São Paulo (2004).

As Atividades Complementares incluíam: Seminários longitudinais sobre Tendências da Educação Matemática, Grupo de Estudo sobre Metodologia de Pesquisa e análise de Pesquisas em Educação Matemática, Autoformação pelo uso das Tecnologias da Informação e Comunicação.

A Prática Docente Supervisionada articulava as disciplinas Didática da Matemática e Desenvolvimento Curricular em Matemática. Complementava a formação do mestrando a elaboração e desenvolvimento do Trabalho Final.

O Trabalho Final, uma atividade de pesquisa, poderia configurar-se na forma de: relato de uma experiência sobre um projeto de intervenção feito em escolas ou salas de aula, programas de formação de professores, programas de atendimento a alunos com dificuldades de aprendizagem. Essa atividade poderia, ainda, caracterizar-se pelo desenvolvimento de recursos didáticos, incluindo a produção de ambientes de aprendizagem: nesse caso, o que seria avaliado era o recurso em si (vídeo, programa computacional, planos de aulas, planos de formação de professores), mas, também, o mestrando deveria produzir um texto que acompanhasse o produto, explicando suas escolhas, como se deu o desenvolvimento dos recursos, e pressupostos teóricos. Poderia ser, ainda, apresentado na forma de uma dissertação sobre o tema investigado pelo mestrando, contendo uma síntese produzida a partir de revisão bibliográfica ou documental, ou o relato sobre estudo(s) de casos, pesquisas de campo, análise de documentos escolares. Enfim, o produto final poderia ser apresentado sob a forma de: análise de casos, desenvolvimento de recursos didáticos, vídeos, programas computacionais, materiais didáticos.

Nas ementas desses diferentes componentes curriculares, foram apontadas as formas de articulação entre conhecimentos teóricos e práticos, buscando-se partir da tematização das práticas docentes para, a partir delas, explorar teorizações da área de Educação Matemática em relação ao campo da didática, do currículo, do uso de tecnologias etc. Desse modo, procuravase uma forma especial de inserção dos professores na pesquisa acadêmica, de modo a valorizar as práticas docentes e a construir novos conhecimentos profissionais. 
Pires, C. M. C.; Igliori, S. B. C.

Quadro 2. Estrutura curricular do curso.

\begin{tabular}{|l|r|c|}
\hline Disciplinas referentes aos Conhecimentos Matemáticos & CH & Créditos \\
\hline Tópicos de Cálculo Diferencial e Integral & 255 & 03 \\
\hline Tópicos de Álgebra & 255 & 03 \\
\hline Tópicos de Geometria & 255 & 03 \\
\hline Tópicos de Matemática Discreta & 255 & 03 \\
\hline Introdução à Filosofia e à História da Matemática & 170 & 02 \\
\hline Disciplinas referentes aos Conhecimentos Didáticos - Pedagógicos & \\
\hline Didática da Matemática & 170 & 02 \\
\hline Desenvolvimento Curricular em Matemática & 85 & 01 \\
\hline Aspectos Cognitivos da Aprendizagem Matemática & 85 & 01 \\
\hline Atividades Complementares & 170 & 02 \\
\hline Seminários longitudinais: Tendências da Educação Matemática & 85 & 01 \\
\hline Grupo de Estudo: Metodologia de Pesquisa e Análise de Pesquisas em Educação Matemática & 255 & 03 \\
\hline Autoformação pelo uso das TIC & 255 & 03 \\
\hline Prática docente supervisionada (articulada à disciplina Didática da Matemática) & 255 & 03 \\
\hline Elaboração e desenvolvimento de Trabalho Final. & \\
\hline
\end{tabular}

Fonte: Pontifícia Universidade Católica de São Paulo (2004).

\section{Perfil dos ingressantes, aspirações e percepções sobre o curso}

No grupo pesquisado, $50 \%$ eram do sexo masculino e $50 \%$ do sexo feminino, sendo $75 \%$ casados e $25 \%$ solteiros. $95 \%$ fizeram sua graduação em instituições privadas e $90 \%$ cursaram a Licenciatura em Matemática. A totalidade lecionava em turmas da Educação Básica, a maioria em escolas da rede pública estadual de São Paulo. Ao responder à entrevista, o grupo estava na fase final do curso, já tendo cursado a maioria das disciplinas e já realizando o trabalho de conclusão.

Esse grupo tinha a idade média de 39 anos. É interessante observar que, segundo Sikes (1985), que realizou estudos para identificar ciclos profissionais segundo a idade, os professores, na fase compreendida entre os trinta e quarenta anos, encontram-se num período de grande capacidade física e intelectual, o que significa energia, envolvimento, ambição e confiança em si mesmos. É uma fase de estabilização, na qual os professores tentam ser mais competentes no seu trabalho e, às vezes, procuram a promoção.

As respostas revelaram que os professores têm clareza no que se refere à necessidade de investimento em seu desenvolvimento profissional e ao desejo de ter uma atuação profissional mais eficaz. Selecionamos alguns depoimentos a esse respeito, optando por não transcrever os que, de alguma forma, reiteravam os motivos já apresentados em outras respostas.

(P1) "Minha grande motivação foi o desejo de me atualizar e estar em contato com estudos e pesquisas, já que estava afastado desde 2000, quando cursei algumas disciplinas no IME-USP”. 
(P2) "Melhorar a qualidade das minhas aulas, pois o nome profissional no curso me motivou muito visto que esta foi a profissão que escolhi”.

(P3) "Com todas essas mudanças que vêm ocorrendo na educação, percebi a necessidade de estar me aperfeiçoando e conhecer novas metodologias de ensino e também uma realização pessoal".

(P4) "A possibilidade de relacionar Educação e Matemática foram decisivas para que eu decidisse por este mestrado".

(P5) “O mestrado em Educação Matemática veio solucionar um problema que eu tinha em relação à pós-graduação, pois queria estudar a matemática na educação e não só matemática como também não queria estudar somente sobre educação. A motivação é melhorar minha qualificação e ingressar no magistério superior".

(P6) "Por ser uma área voltada para a educação e em especial Educação Matemática o curso me motivou, pois a discussão sobre a educação nos leva a muitos questionamentos e essa descoberta na educação tem me motivado para melhorar minha atuação em sala de aula".

(P7) "O desejo de saber mais, de me aperfeiçoar cada vez mais e poder contribuir para que ensino da matemática seja algo realmente atrativo, em que a ciência chamada Matemática deixe de ser motivo de medo para os alunos e passe ser o que ela realmente é".

(P8) "Por ser um sonho almejado desde a adolescência, e interrompido por vários motivos e pela vontade de aprender mais e poder ampliar meus conhecimentos na área".

(P9) "Decidi fazer o curso para poder continuar estudando e poder melhorar, cada vez mais meu trabalho, além da obtenção do título.

(P10) "Com certeza, a minha carreira profissional, para buscar e oferecer o melhor que se tem da Matemática. Com isso, tracei metas para atingir após o ingresso no MP. Em primeiro lugar, buscar e manter a atualização e capacitação sobre a Educação Matemática e, em seguida, dar continuidade nos estudos e na atuação na educação, não só como professora de educação básica, mas também, superior".

(P11) "As disciplinas apresentadas pelo curso me agradaram muito e também a necessidade do título de Mestre para poder trabalhar também no ensino superior". 
Pires, C. M. C.; Igliori, S. B. C.

Em três depoimentos, as motivações apresentadas foram complementadas por referências à vantagem representada pela bolsa de estudos da Secretaria da Educação do Estado de São Paulo:

(P5) “Também a vantagem da bolsa mestrado oferecida pela Secretaria de Educação, visto que sem ela não teria condições de fazê-lo e ao mesmo tempo aumentar meu conhecimento na área da Educação Matemática”.

(P12) Minha necessidade contínua de atualização para ministrar aulas adequadas com os requisitos do mundo atual e sem contar que a bolsa mestrado teve uma ajuda muito especial".

(P9) "Também contou o incentivo do governo com bolsa parcial, e grande vontade de crescer profissionalmente".

$\mathrm{Na}$ coleta de dados, procuramos conhecer a opinião do grupo de alunos pesquisados relativamente à interferência que o Mestrado Profissional pode desempenhar no seu desenvolvimento profissional e na sua atuação docente. Alguns depoimentos demonstram que os professores conferem especial importância à formação que se articula com sua ação diária e valorizam os saberes profissionais situados, construídos e utilizados em função de uma situação de trabalho particular, e ganham sentido nessa situação. Essa influência das aprendizagens no curso na prática em sala de aula foi a tônica dos depoimentos.

(P3) "Minhas aulas mudaram bastante este ano. Quando as preparo reflito sobre várias questões tratadas no curso. O caráter investigativo na abordagem dos assuntos tem sido prioridade. Acredito que estou motivando muito mais os alunos e tornando-os pessoas mais autônomas, na medida em que a exposição dos conceitos e procedimentos tem sido precedida, quase sempre, por um processo de discussões com conjecturas e refutações dos alunos, na minha visão, muito enriquecedoras ao trabalho".

(P5) "Estou mais motivada e aprendendo muito, as aulas que tive até hoje têm me ajudado a refletir sobre minha postura e de certa forma dos meus colegas. Acredito que ainda seja cedo para fazer uma análise em meu desenvolvimento profissional, porém o que sinto até aqui, foi a minha mudança frente a algumas situações, poderia chamar de fase de amadurecimento profissional. Está influenciando na minha prática, pois aprendi muitas coisas que consegui aplicar e ter um olhar diferente para a relação professor-aluno".

(P8) "Interferiu na consciência de que, realmente, há uma Matemática muito mais ampla do que a Matemática que aprendi, vivenciei e que 
hoje ofereço aos meus alunos. O curso está interferindo na mudança de estratégias, metodologias e planejamento do que ofereço aos meus alunos com relação ao ensino da Matemática. Melhor observação e análise de ações e reflexões dos alunos nos diversos momentos de sua aprendizagem".

(P10) "No meu caso, proporcionou-me uma confiança maior no meu poder de argumentação teórica sobre o conteúdo da disciplina, conseguindo relacionar os fatos históricos com as necessidades atuais. Aprendi dar maior importância ao desenvolvimento histórico matemático e introduzi-lo no conteúdo da minha disciplina".

(P13) "Está confirmando minhas antigas convicções quanto ao processo de ensino e de aprendizagem junto aos meus alunos. Tenho necessidade de fazer melhor. $\mathrm{O}$ curso faz refletir sobre o que e como ensinar".

(P16) "Mudou muito, pois me fez rever conceitos, mudar de comportamento, ler mais e buscar mais informações com o objetivo de melhorar a qualidade de minhas aulas de matemática".

(P20) "Muitas coisas que não faziam parte das minhas práticas pedagógicas mudaram principalmente o uso de informática, no mestrado tive a oportunidade de cursar uma disciplina que seu enfoque era exatamente este, ainda preciso estudar mais o uso de tecnologia, mas ele já é uma realidade nas minhas aulas. Profissionalmente está sendo importante o contato com pesquisas, pessoas que trabalham na área, troca de experiências e também percebo que estou sendo mais valorizado no mercado de trabalho".

Alguns depoimentos revelaram preocupação e anseio dos mestrandos em atuar como formadores de outros professores:

(P13) "Desde que ingressei no Mestrado Profissional, tenho lido bastante e procurado trazer as aprendizagens para minha unidade escolar, durante as HTPC. Realizando oficinas com os professores, tem sido possível uma utilização da sala de informática de modo sistemático".

(P22) "Ao refletir sobre as mudanças em minha prática me sinto um pouco incomodado pelo fato de que nem todos os colegas estão envolvidos em cursos como esses. E no espaço da escola também temos poucas oportunidades até de conversar sobre o que estamos aprendendo aqui". 
Pires, C. M. C.; Igliori, S. B. C.

Outro ponto marcante nas respostas foi a referência ao uso de novas tecnologias. Selecionamos alguns depoimentos a título de exemplificação, ressaltando, porém, que em quase todas as repostas os professores destacaram o uso de tecnologias como algo muito novo para eles.

(P2) "O uso da informática, o contato com pesquisa em educação matemática, são as coisas mais significativas até agora. O uso de informática era nulo até iniciar o mestrado, hoje já é uma realidade que posso trabalhar e contribuir mais significativamente na formação dos alunos. O contato com pesquisa em educação matemática permite estar interado das coisas que estão acontecendo no Brasil e também em outros países; isto faz eu repensar sobre minhas práticas pedagógicas".

(P4) "Desenvolvimento com os alunos e o ambiente escolar e aquisição de novos conceitos e conhecimentos das novas tecnologias emergentes que são fundamentais para a formação de um educando plenamente cidadão".

(P7) "A utilização do Cabri Geometre, a metodologia WEBQUEST (em que elaboramos uma atividade sobre Pirâmides); fiz oficinas com professores e alunos sobre a utilização do Power Point. O contato com Revistas especializadas, a análise de um livro didático com base em determinados critérios, a leitura de artigos a partir de assuntos tratados em aula. Os assuntos trabalhados em Tópicos de Cálculo e a utilização do software Imagiciel".

(P9) "A disciplina Autoformação pelo uso das TIC nos deu subsídios para iniciarmos um trabalho inovador e motivador. Se utilizarmos as tecnologias com inteligência, questionando seu uso, suas vantagens, etc., nossa prática docente será bastante beneficiada por conta desta disciplina".

(P12) "Já estou usando ferramentas tecnológicas disponíveis que temos como o Winplot, Graphmat, Cabrigeometre, Web Quest entre outras, muitas de graça que podemos criar e inovar no ambiente escolar. Isso é inacreditável, considerando que eu era bastante desinformatizada".

(P25) "O uso dos softwares educacionais na sala de aula. Como o Cabrigeometre para trabalhar geometria e o Winplot para trabalhar gráficos". 
(P28) "O uso dos softwares em sala de aula, tornando as aulas mais interessantes. O manuseio desses softwares acrescentou muito na minha prática".

(P13) "Elaboração de Webquest, muito significativa porque quando orientei professores e alunos observei excelentes resultados".

Solicitados a identificar as aprendizagens realizadas no Mestrado Profissional que consideravam significativas para sua formação, os professores construíram um diversificado repertório. Categorizamos as respostas, reunindo, primeiro, as referências relativas a conhecimentos matemáticos e, na sequência, as relativas a conhecimentos didáticos e curriculares:

(P12) "Aplicações das funções, como estar construindo este conceito com os alunos, organizando seqüências didáticas, a resolução de problemas, como devemos formalizar conceitos".

(P17) “Álgebra e Tópicos de Geometria tiveram importantes papéis na nossa formação: revisão de alguns conteúdos que não trabalhávamos desde a graduação e uma boa base para um possível trabalho docente em cursos de graduação".

(P22) "A disciplina de geometria me fez repensar a minha maneira de ensinar e aprender".

(P24) "Atenção maior no rigor matemático das demonstrações em Álgebra e Geometria e a importância das demonstrações; questiono por que muitos livros didáticos não apresentam demonstrações”.

(P27) "O rigor matemático no que falo e escrevo e buscar saber o significativo de regras, fórmulas etc".

(P30) "Para mim foram as mais importantes as aprendizagens nas aulas de Geometria, que eu desconhecia em grande parte".

(P7) "O contato com questões e temas que envolvem a Didática da Matemática, pois nos ajudam a entender de forma mais clara o que acontece no processo ensino-aprendizagem".

(P16) "Gostei de conhecer a teoria das Inteligências Múltiplas que vai me ajudar a entender melhor a relação dos meus alunos com a matemática e a compreender outras manifestações da inteligência". 
Pires, C. M. C.; Igliori, S. B. C.

(P18) "A importância de compreender a trajetória histórica do desenvolvimento matemático e as relações com a história que posso estabelecer no processo de ensinar matemática".

(P22) "Uma das aprendizagens práticas foram as formas de trabalho em grupo, como fazer para que ele seja bem desenvolvido de forma a envolver todos os participantes e a construir conhecimentos".

(P25) "A necessidade de conhecer os currículos e as propostas: o mestrado profissional mudou a forma como eu via as propostas curriculares, os planos e as formas de planejar, pois para que o ensino da matemática possa melhorar é de fundamental importância que os professores conheçam as propostas, estudem-nas e as explorem em sala de aula".

(P14) "A teoria dos Campos Conceituais que eu não conhecia. Ainda preciso saber mais sobre ela, mas deu para começar a perceber o alcance das pesquisas".

(P17) "Uma das melhores aprendizagens foi o contato com pesquisas em Educação Matemática. Aprendi como estar informado sobre coisas que estão acontecendo no Brasil e também em outros países; isto vem me fazendo repensar sobre minhas praticas pedagógicas".

Em suas respostas, os professores/mestrandos fizeram diversos comentários sobre "atividades" desenvolvidas ao longo do curso e que despertaram especial interesse. Nesses depoimentos, foi possível perceber que eles valorizaram não somente as "aulas", mas, também, demonstraram interesse por outras atividades curriculares como: seminários, palestras, levantamentos sobre projetos pedagógicos e curriculares nas escolas.

Como foi ressaltado anteriormente, o curso de Mestrado Profissional foi concebido como espaço de construção de conhecimentos pedagógicos e didáticos, articuladores de teoria e prática. Visava à construção, pelos alunos-professores, de novas aprendizagens, novas práticas profissionais, mas, sobretudo, de uma nova atitude profissional, ou seja, pretendia estimular professores a assumir o protagonismo de seu processo de formação e desenvolvimento profissional, tomando iniciativas, buscando informação e formação, desenvolvendo seus projetos, avaliando seu trabalho. Com tal intenção, o estímulo às atividades de leitura e escrita foi preocupação e investimento comum das diferentes atividades curriculares, assim como a aproximação dos alunos-professores das pesquisas na área da Educação Matemática. Como mostram os depoimentos, essas intenções foram percebidas. Selecionamos alguns exemplos que transcrevemos na sequência:

(P2) "Foi muito interessante o seminário sobre Poliedros utilizando o software Cabri. O acesso a todo tipo de material que pudesse subsidiar

1060

Ciênc. Educ., Bauru, v. 19, n. 4, p. 1045-1068, 2013 
o trabalho: revistas, livros, internet a procura do assunto e o próprio tempo destinado ao manuseio do software Cabrigeometre para a confecção dos sólidos, buscando utilizar todos os conceitos sobre isometria adquiridos durante as aulas e culminando com a criação dos puzzles. Foi um trabalho que realmente contribuiu e muito para a minha formação".

(P4) "Foi muito útil o seminário apresentado em TIC, mostrando a Webquest como uma excelente ferramenta didática”.

(P7) "O debate sobre livro didático foi muito importante. A visão na análise dos livros frente a um referencial teórico me fez ver, o quanto é importante estar a par dessas teorias. Só assim podemos ver, diante das atividades sugeridas pelos autores, a concepção utilizada e o tipo de aluno pode ser formado".

(P9) "Em várias disciplinas fizemos análise de seqüências didáticas que os livros didáticos trazem e que nós como educadores podemos interferir para buscar um maior rendimento para nossos alunos, reorganizando seqüências apropriadas para nossos alunos”.

(P15) "Fazer visita monitorada ao Centro de Referência Mário Covas e pesquisar documentos curriculares de vários períodos, permitindo reconstruir parte da história da educação matemática, que eu desconhecia totalmente".

(P18) "Gostei muito do trabalho de campo em escolas da rede pública analisando documentos curriculares e entrevistando professores".

(P21) "Participar das reuniões feitas durante os finais de semana com colegas do grupo de estudos, pesquisas em escolas, livros, internet, preparação dos assuntos a serem apresentados em seminários nas aulas".

(P23) "Para mim foi excelente a elaboração de um Portfólio: não sou organizada, não tenho hábito de fazer registros, sínteses; aprendi que o portfólio pode ser usado como um importante instrumento de avaliação".

(P27) "Uma das atividades foi a pesquisa junto aos professores da escola pública, sobre aplicação das propostas curriculares, pois através dessa pesquisa pude ver o quanto o ensino da matemática vem sendo feito de maneira inadequada e improdutiva".

1061

Ciênc. Educ., Bauru, v. 19, n. 4, p. 1045-1068, 2013 
Pires, C. M. C.; Igliori, S. B. C.

(P30) "Elaborar relatórios sobre as aulas de Didática da Matemática também são muito positivos, pois eles nos fazem refletir sobre os assuntos tratados naquela aula".

Relativamente à contribuição do curso para ampliação de seu universo cultural, os depoimentos de professores transcritos na sequência referem-se especialmente a leituras complementares que fizeram e que se mostraram importantes:

(P2) "O livro As ideias da Álgebra que li por sugestão da disciplina Didática da Matemática me interessou bastante. Gosto de álgebra e os artigos ali inseridos são de alta qualidade. O que mais me chamou a atenção neste texto foi o tratamento dispensado à questão do significado em álgebra".

(P4) "Um artigo sobre modelagem matemática no ensino médio me agradou pelo enfoque de modelagem que o autor deu, e não simplesmente alguns problemas aplicados".

(P9) "O capítulo do livro História da Matemática, sobre a construção da tabela trigonométrica por Ptolomeu, mostrando toda necessidade desta tabela nos trabalhos de astronomia que é uma área que particularmente me interessa muito".

(P12) "Assistir ao filme "Être e avoir" e poder discuti-lo com a professora e com os colegas".

(P13) "Gostei de um artigo sobre a introdução da função no ensino secundário no Brasil, por Euclides Roxo. $\mathrm{O}$ artigo retrata muito bem como é a política educacional no país. Mostra que tudo é atrelado a interesses políticos da época”.

(P16) "O livro Último Teorema de Fermat, proposto pela professora de Desenvolvimento Curricular. Um livro encantador que faz um passeio pela história citando matemáticos e suas contribuições para esse desafio do Teorema de Fermat".

(P24) "O Currículo com Abordagem Etnomatemática, publicado em Educação Matemática em Revista da SBEM, me chamou a atenção pela proposição de reflexões críticas sobre o currículo escolar, muitas vezes imposto aos alunos sem que se leve em consideração seus anseios e o contexto político, social e cultural em que estão inseridos". 
(P25) "Entre os livros que pesquisei o que mais chamou a atenção foi o livro Número: a Linguagem da Ciência, de Tobias Dantzig, em que autor apresenta a evolução do conceito de número, utilizando a história da Matemática, numa linguagem atual e muito envolvente".

Nesse grupo de alunos, 30\% deles afirmaram não ter dificuldades para acompanhar o curso. Dentre os $70 \%$ que declararam sentir dificuldades, há menções à falta de tempo e também ao fato de estarem há algum tempo distantes dos estudos.

(P2) "Tive dificuldades para preparar as atividades propostas, pois precisavam de muita pesquisa, fora o pouco tempo que sobrava para estudar depois de todas as aulas e atividades semanais".

(P10) "Como no primeiro semestre não tinha bolsa mestrado a preocupação estava muito maior, porque além de estudar, ainda tinha o compromisso financeiro. No segundo semestre fui efetivado no estado e passei a fazer parte do programa bolsa mestrado. Isso está me dando uma tranqüilidade maior, podendo assim se dedicar melhor aos estudos".

(P14) "Devido ao tempo em que terminei minha graduação (1996) e o início do mestrado (2004). Na graduação não tive a oportunidade de me aprofundar em determinados assuntos e isso agora está fazendo diferença".

(P18) "Todas as disciplinas exigiram dos alunos uma base sólida, que muitos não têm, então era necessário um empenho maior para superar suas dificuldades. As disciplinas, Tópicos de Geometria e Tópicos de Álgebra foram as disciplinas que mais necessitaram de uma base teórica que não foi dada na minha formação".

(P23) "Meus problemas foram motivados pela falta de disponibilidade de tempo para me dedicar integralmente ao Mestrado".

(P24) "A distância da família, os recursos financeiros e alguns conteúdos dos quais eu estava afastada há muito tempo por não lecionar no Ensino Médio ou Superior". 
Pires, C. M. C.; Igliori, S. B. C.

\section{Temas focalizados nos trabalhos finais}

Como nossa pesquisa dedicou-se ao acompanhamento do curso durante o período de 2002 a 2008, além da primeira turma de 31 alunos, estendemos nossa investigação relativa a temas abordados nos trabalhos de conclusão, para alunos de turmas posteriores, num total de 100 trabalhos. Na Tabela 1 apresentamos dados de concluintes do curso até 2008, período em que foi realizada nossa pesquisa, e indicamos os alunos bolsistas da Secretaria da Educação do Estado de São Paulo 5 .

Tabela 1. Alunos do MP concluintes por ano.

\begin{tabular}{ccc}
\hline Ano & Concluintes & Bolsistas da SEE-SP \\
\hline 2004 & 01 & 00 \\
2005 & 16 & 00 \\
2006 & 15 & 00 \\
2007 & 56 & 45 \\
2008 & 47 & 29 \\
Total & 135 & 74 \\
\hline
\end{tabular}

Fonte: Dados compilados pelas autoras.

De modo geral, os trabalhos de conclusão foram feitos na forma de dissertações, com complementos em forma de produtos para possível uso por outros professores de Matemática. Analisando os cem primeiros trabalhos concluídos, observamos que $24 \%$ deles tiveram como foco temas relativos à Álgebra, tratando de uma gama variada de assuntos: Sistemas lineares "Escritas algébricas " Números inteiros " Ensino das operações com números inteiros “ Razões e proporções " Tabela trigonométrica " Fatorial - Padrões - Números irracionais "Habilidades de Resolução problemas "Padrões e sequências " Conceito de função "Termo geral da P.A. “ Álgebra nos livros didáticos - Razões trigonométricas " Critérios de divisibilidade " Jogos matemáticos " Pensamento proporcional " Uso da modelação matemática " Estruturas multiplicativas " Diferentes linguagens " Abordagem para introdução à álgebra " Livro didático " Discurso do professor " Propostas de ensino - Sequência de ensino "Situações de aprendizagem " Uso da calculadora “ Observação e generalização de padrões.

Essa prioridade pode estar relacionada ao fato de que os professores mestrandos, majoritariamente, atuavam em salas dos anos finais do Ensino Fundamental e no Ensino Médio e, desse modo, demonstravam interesse em investigar problemas que os desfiavam em sua prática profissional.

${ }^{5}$ Até o final de 2011, titularam-se 236 alunos nesse Mestrado Profissional, sendo cento e cinquenta bolsistas da Secretaria da Educação do Estado de São Paulo. 
Na sequência, com cerca de $20 \%$, apareceram trabalhos focalizando a organização e o desenvolvimento curricular, abordando temas como: currículos prescritos e implementação na sala de aula, por que ensinar Matemática, currículos praticados, atitudes e procedimentos de alunos perante à Matemática, Etnomatemática, currículos do Movimento da Matemática Moderna ao período atual, Resolução de Problemas e investigações, Matemática e Cidadania, perspectivas construtivistas, currículos e livros didáticos, leitura e interpretação de textos matemáticos, e a presença e abordagem de temas específicos nos currículos, por exemplo, razões e funções trigonométricas, noções iniciais de probabilidade, funções, geometria espacial etc.

Os trabalhos focalizando as Tecnologias da Informação e da Comunicação totalizaram cerca de 20\%. Abordando temas variados de Álgebra, Geometria, Estatística, a ênfase dos trabalhos concentrava-se no uso de: Cabri, Cabri 3D, Calculadoras, Celulares, Internet, Hot potatoes, Graphmatica e Webquest.

Formação de professores foi o foco de $16 \%$ dos trabalhos envolvendo análises da formação inicial, continuada, e prática docentes: Cursos de Pedagogia, Cursos de Licenciatura em Matemática, Estágio curricular supervisionado, Inter-relações entre universidade e escola básica, Perfil do Professor formador, Prática como componente curricular, Estudo comparativo de materiais para formação de professores das séries iniciais, práticas na sala de aula, desafios da formação continuada, professores das séries iniciais em começo de carreira, professores de Matemática do Ensino Fundamental II em início de carreira, recursos da Internet usados pelos professores, dificuldades, dilemas e saberes dos professores da Educação Básica.

Os temas ligados ao ensino da Geometria totalizaram 9\%, e foram apresentadas situações de ensino e sequências didáticas para assuntos diversificados, como: Semelhança, Congruência, Isometrias, Geometria esférica, Geometria Espacial, Geometria Métrica, Quadriláteros, Argumentação Prova no Ensino Fundamental, Perspectiva, Conexão com a Geografia a Ciência e a Arte.

Verificamos, ainda, que os trabalhos sobre Educação Estatística totalizaram 7\% e trataram de diferentes temas, como: Letramento estatístico, Medidas separatrizes, Distribuição normal, Leitura, interpretação de gráficos e tabela variabilidade, Simulações via planilha eletrônica e exercícios interativos, examinando livros didáticos e trabalhando com sequências didáticas e análise de desempenho dos estudantes.

Trabalhos envolvendo o ensino do Cálculo totalizaram 3\%, e temas variados, como inclusão e diversidade, $2 \%$.

\section{Considerações finais}

As análises indicaram a pertinência da modalidade de pós-graduação na formação dos professores de Matemática. As referências teóricas do projeto sustentaram a qualidade da formação na medida em que houve espaço, tema e conteúdos que abriam possibilidades para a relação pesquisa e prática e o envolvimento do profissional em sua formação, com possibilidade de diagnósticos das suas demandas e busca de respostas às mesmas, por meio de resultados de pesquisa. Como docentes e investigadores desse curso, pudemos perceber: que a formação do professor, para o exercício da sua atividade profissional, é um processo que envolve inserções em diferentes domínios de conhecimento; que é importante adotar a con- 
cepção do professor como pesquisador; e tornar possível o desenvolvimento da prática da pesquisa articulada com o trabalho docente. Isto nos remete a destacar esses elementos como imprescindíveis na constituição do profissional, professor de Matemática, e, assim sendo, recomendar o estudo da temática aos formadores e pesquisadores, especialmente quando se observam retrocessos nessa perspectiva.

A entrevista, a análise dos documentos e nossa prática como docente do curso nos permitiram dizer que: um Mestrado Profissional, e, no caso particular, um Mestrado Profissional em Educação Matemática, se diferencia das especializações e dos Mestrados Acadêmicos na medida em que toma a problemática diária da sala de aula por investigação embasada em resultados de pesquisa (no desenvolvimento das atividades de formação e na elaboração e desenvolvimento dos trabalhos finais). E, como tal, tem identidade, qual seja a de constituir um momento da formação continuada do professor de Matemática de modo a propiciar sua evolução profissional em consonância com o desenvolvimento da pesquisa. E devem ser esses os pressupostos definidores do projeto curricular de um MP. As demandas de formação devem ser aquelas indicadas pelo professor/mestrando de forma dinâmica e atrelada à sua prática docente.

No caso específico do curso em estudo, seu projeto se revelou consistente com as referências teóricas, propiciando uma formação, ao professor, em consonância com seus anseios, o que pode ser detectado nas respostas dos professores/mestrandos. Eles se revelaram professores preocupados com seu desenvolvimento profissional, que identificavam suas necessidades de formação relativa a conteúdos matemáticos, mas, também, didáticos e curriculares.

De modo geral, apontaram claramente falhas em sua formação inicial, especialmente para promover a aprendizagem de seus alunos. Essas constatações reforçam os alertas de diferentes teóricos já citados neste artigo, e nos remetem aos trabalhos desenvolvidos por Ball (1988), que discute três concepções acerca da formação de professores, largamente adotadas, a saber: (1) Se os futuros professores sabem resolver questões que envolvem assuntos básicos, então, poderiam ensinar; (2) Se os conteúdos da "matemática escolar" são simples e comumente entendidos, então, os futuros professores não precisariam revê-los; (3) Se o indivíduo tem uma formação universitária que envolve o estudo de matemática, isto lhe dará um grande conhecimento do assunto e, assim, ele estaria apto a ensiná-la, ainda que não tenha nenhuma formação pedagógica.

Outro destaque a ser feito refere-se ao fato de que os professores mestrandos foram percebendo a necessidade de mudança de sua relação com o conhecimento, com a necessidade de aprender a aprender, e de buscar, com certa autonomia, as informações de que precisam para sua atuação profissional.

Finalizamos este artigo revelando que tal projeto do curso precisou ser reformulado. A nosso ver, pelo fato de que a proposta de realizar os Mestrados Profissionais em dois anos dificultava a manutenção desse modelo de formação.

\footnotetext{
${ }^{6}$ Desde sua implantação até julho de 2013, foram titulados em torno de duzentos e trinta mestres profissionais em Ensino de Matemática na PUC-SP.
} 
Mestrado Profissional e o desenvolvimento ...

A estrutura curricular do curso, tal como indicada neste artigo, funcionou de agosto de 2004 a agosto de 2011.

Retomando questões apresentadas no início deste artigo, certamente, ainda permanecem alguns questionamentos sobre a identidade dos Mestrados Profissionais em Educação de Matemática e, consequentemente, sobre como organizar a estrutura curricular desse curso em função das demandas de formação a serem atendidas. Mas alguns indicadores nos oferecem pontos bastante seguros e claros como, por exemplo, o que esperam os ingressantes nesses cursos.

Certamente, os depoimentos sobre as motivações para cursar o Mestrado Profissional e sobre a interferência do curso no desenvolvimento profissional e na atuação docente nos permitem inferir que tal modalidade de curso pode representar um espaço de desenvolvimento profissional para os professores de Matemática, segundo as características dadas a esse desenvolvimento neste artigo.

Além das revelações contidas nos depoimentos dos próprios professores, destacaríamos, como ponto fundamental no acompanhamento do processo de implementação desse curso, a construção de uma alternativa de aproximação entre os mundos da "pesquisa acadêmica" e da "pesquisa profissional", preenchendo a necessidade, destacada por autores, como Zeichner (1992), de eliminar a separação que existe entre o mundo da pesquisa educacional acadêmica e o mundo dos professores pesquisadores.

Em nossa avaliação, os Mestrados Profissionais podem ser espaço importante para dar visibilidade ao conhecimento que os professores produzem, mas é preciso garantir as condições que viabilizem: sua participação, momentos de estudo, tempo para investigações com oferta de incentivo para os que continuem atuando na Educação Básica.

\section{Referências}

ANDERSON, G. L.; HERR, K. The new paradigm wars: is there room for rigorous practitioner knowledge in schools and universities? Educational Researcher, Washington, v. 28, n. 5, p. 12-21, 1999. Disponível em: <http://www.jstor.org/stable/1176368>. Acesso em: 30 out. 2013.

BALL, D. L. Knowledge and reasoning in mathematical pedagogy: examining what prospective teachers bring to teacher education. 1988. $271 \mathrm{f}$. Dissertation (Doctor of Philosophy) - Department of Teacher Education, College Education, Michigan State University, East Lansing, 1988.

BOAVIDA, A. M.; PONTE, J. P. Investigação colaborativa: potencialidades e problemas. In: GRUPO DE TRABALHO DE INVESTIGAÇÃO (Org.). Reflectir e investigar sobre a prática profissional. Lisboa: APM, 2002. p. 43-55.

COCHRAN-SMITH, M; LYTLE, S. L. The teacher research movement: a decade later. Educational Researcher, Washington, v. 28, n. 7, p. 15-25, 1999. Disponível em: <http:// dx.doi.org/10.3102/0013189X028007015>. Acesso em: 30 out. 2013. 
Pires, C. M. C.; Igliori, S. B. C.

DONAIRE, D. A utilização do estudo de casos como método de pesquisa na área da administração. Revista Imes, Santo André, v. 14, n. 40, p. 9-19, maio-Ago./1997.

ELBAZ, F. Teacher thinking: a study of practical knowledge. London: Croom Helm, 1983.

PERRENOUD, P. Novas competências para ensinar. Porto Alegre: Artmed, 2000.

PONTE, J. P. Concepções dos professores de matemática e processos de formação. In: BROWN, M. et al. (Ed.). Educação e matemática: temas de investigação. Lisboa: IIE, 1992. p. 186-239. Disponível em: < http://www.educ.fc.ul.pt/docentes/jponte/DOCS-PT/ 92-ponte(Ericeira).doc $>$. Acesso em: 5 jun. 2003.

PONTIFÍCIA UNIVERSIDADE CATÓLICA DE SÃO PAULO. Projeto curricular do curso de mestrado profissional em ensino de matemática. São Paulo: PUCSP, 2004. Disponível em: <http://www3.pucsp.br/educacao-matematica>. Acesso em: 01 nov. 2013.

SARAIVA, M.; PONTE, J. P. O trabalho colaborativo e o desenvolvimento profissional do professor de Matemática. Quadrante, Lisboa, v. 12, n. 2, p. 25-52, 2003. Disponível em: <http://repositorio.ul.pt/bitstream/10451/3077/1/03-Saraiva-Ponte(Quadrante).pdf>. Acesso em: 01 nov. 2013.

SIKES, P. The life cycle of the teacher. In: BALL, S. J.; GOODSON, I. F. (Ed.). Teachers' lives and careers. London: The Falmer Press, 1985. p. 67-70.

TARDIF, M. Saberes docentes e formação profissional. Petrópolis: Vozes, 2002.

ZEICHNER, K. A formação reflexiva de professores: ideias e práticas. Lisboa: Educa, 1993.

Novos caminhos para o praticum: uma perspectiva para os anos 90. In: NÓVOA, A. (Coord.). Os professores e sua formação. Lisboa: Dom Quixote, 1992. p. 115-138.

Artigo recebido em 05/02/13. Aceito em 08/06/13. 